\title{
The size and inter-annual variability of forest biomass carbon pool in
}

\section{China}

\author{
J.N. YANG ${ }^{1} \&$ H.Y. LI ${ }^{1}$ \& L.Y. LV ${ }^{1}$ \\ ${ }^{1}$ College of Environmental Science and Engineering, Nankai University, Tianjin 300071, China
}

\begin{abstract}
KEYWORD: Forest; Biomass; Carbon Pool
ABSTRACT: It has very important significance to assessing forest biomass carbon pool and its inter-annual variability accurately for the reveal the role of forests in terrestrial ecosystem carbon cycle and the rational utilization of forest resources. We are trying to explain the size of the biomass carbon pool and its inter-annual variability in China by reviewing the latest progress in the study of China's forest biomass carbon pool. The results showed that, (1) The biggest difference of China's forest biomass carbon pool in the same period between different researchers was $2813.5 \mathrm{Tg}$, and the biggest difference of carbon density was $19.20 \mathrm{Mg} / \mathrm{ha}$. The differences between different researchers are largely the results of the difference in biomass estimation and coefficient of carbon. (2) In 1949-2008, the size of the biomass carbon pool decrease at first and then increase. The change of carbon density is fluctuant.
\end{abstract}

\section{Introduction}

Forest biomass carbon stock is an important proportion of the carbon stock in terrestrial ecosystems, playing an important role in global carbon cycle [1-4]. It is the biggest stock in terrestrial ecosystems. Forest biomass accounts for $85 \%$ to $90 \%$ of the total global terrestrial vegetation biomass [5-7]. The carbon exchange between forest and atmosphere accounts for $90 \%$ of the terrestrial ecosystem carbon exchange capacity annually. "Kyoto Protocol" made it clear that afforestation and reforestation have important effects on offsetting greenhouse gas emissions. Forest area is broad in China, ranking it fifth globally. And the forest types were rich. So it's advantageous to research on forest ecosystem carbon cycle [8]. Since the 1970s, the forest plantation and protection were large-scale carried out in China, which made the forest as a carbon pool [9-13]. In this article, we are trying to explain the size of the biomass carbon pool and its inter-annual variability in China and discuss combined problems by reviewing the latest progress in the study of China's forest biomass carbon pool.

\section{The size and difference of forest biomass carbon pool}

In the late 1990s, many researchers estimated the size of forest biomass carbon pool in China(see Table 1). The findings are various between different researchers. The estimates of forest biomass carbon pool in China were 3696-9240Tg, and the maximum is about 2.5 times as many as the minimum. The averages of biomass carbon density were $35.56-57.07 \mathrm{Mg} / \mathrm{ha}$, and the maximum is about 1.6 times as many as the minimum. The differences mainly come from the difference between different periods. During the same period, the differences between the estimates is less than 2813.5Tg, and the differences between the biomass carbon density is less than $19.20 \mathrm{Mg} / \mathrm{ha}$. The difference between Zhao et al and Guo et al that estimated the forest biomass carbon pool in 2004-2008 was 2813.5Tg, which is the biggest difference. It's mainly because of the different estimation methods. Fang et al estimated the forest biomass carbon pool during 1989-1993 with continuous BEF function method, and the result was 4630Tg. Xu et al estimated the carbon stock with the fitted relation between biomass and volume based on trees, and the finding was 4113.8Tg. $\mathrm{Wu}$ et al estimated the carbon pool with the method of IPCC, showing 4220.45Tg. The above three findings are close, but is much less than the estimation of Zhou et al, which was 6200Tg. Zhou et al 
used the data come from Dixon R.K, which is so different with the situation of China, so it not included in the later discussion.

Table 1 Forest carbon stock and carbon density in China from different studies

\begin{tabular}{|c|c|c|c|c|}
\hline Reference & Period & $\begin{array}{c}\text { Biomass } \\
{[\mathrm{Tg}]}\end{array}$ & $\begin{array}{c}\text { Carbon } \\
\text { stock }[\mathrm{Tg}]\end{array}$ & $\begin{array}{l}\text { Carbon } \\
\text { density } \\
{\left[\mathrm{Mgha}^{-1}\right]}\end{array}$ \\
\hline \multirow{7}{*}{14} & 1973-1976 & 7697.5 & 3848.8 & 35.56 \\
\hline & 1977-1981 & 7392 & 3696 & 38.65 \\
\hline & 1984-1988 & 7517.9 & 3759 & 36.78 \\
\hline & 1989-1993 & 8227.5 & 4113.8 & 37.87 \\
\hline & 1994-1998 & 9312.6 & 4656.3 & 36.04 \\
\hline & $1999-2003$ & 11012.9 & 5506.4 & 38.56 \\
\hline & 1949 & 10122.2 & 5060 & 49.45 \\
\hline \multirow{6}{*}{15} & $1950-1962$ & 9153.5 & 4580 & 46.67 \\
\hline & 1973-1976 & 8876.2 & 4440 & 43.83 \\
\hline & 1977-1981 & 8750 & 4380 & 45.75 \\
\hline & 1984-1988 & 8896.5 & 4450 & 43.53 \\
\hline & 1989-1993 & 9250.1 & 4630 & 42.58 \\
\hline & 1994-1998 & 9504.5 & 4750 & 44.91 \\
\hline 16 & 1989-1993 & 13777.8 & 6200 & 57.07 \\
\hline \multirow[t]{2}{*}{17} & 1989-1993 & 7556.2 & 3778.1 & 41.32 \\
\hline & $1977-1981$ & 9434 & 4717 & 38.2 \\
\hline \multirow{5}{*}{18} & 1984-1988 & 9770 & 4885 & 37.1 \\
\hline & 1989-1993 & 10804 & 5402 & 38.7 \\
\hline & 1994-1998 & 10776 & 5388 & 40.7 \\
\hline & $1999-2003$ & 11724 & 5862 & 41.1 \\
\hline & 2004-2008 & 12854 & 6427 & 41.3 \\
\hline \multirow[t]{2}{*}{19} & 1984-1988 & - & 3724.5 & - \\
\hline & 1989-1993 & - & 4220.45 & - \\
\hline \multirow[t]{2}{*}{20} & 1994-1998 & - & 4646.94 & - \\
\hline & $1999-2003$ & - & 5156.71 & - \\
\hline 21 & 2004-2008 & - & 9240.5 & - \\
\hline
\end{tabular}

The forest biomass carbon stock equals forest biomass times the carbon content. It's a universal way to estimate forest carbon stock. So forest biomass and carbon content of trees are the keys to the estimation, there are also the sources of differences.

\section{The difference of estimation methods}

Fang et al divided the forest in China into 21 types based on 758 groups of data about biomass and volume. They calculated the relationship between BEF and volume of each forest type. The equation is below.

$$
\mathrm{B}=\mathrm{aV}+\mathrm{b}
$$

where $\mathrm{a}$ and $\mathrm{b}$ are constant; $\mathrm{B}$ is biomass; $\mathrm{V}$ is volume. The findings with this method were 8896.5Tg during 1984-1988 and 9250.1Tg during 1989-1993.

$\mathrm{Xu}$ et al estimated the carbon stock with the fitted relation between biomass and volume based on trees.

$$
B_{i j}=\mathrm{a} V_{i j}+\mathrm{b}
$$


where $B_{i j}$ is the biomass of a certain type forest with a certain age; $V_{i j}$ is the volume of a certain type forest with a certain age; $a$ and $b$ are constant. The findings with this method are $7517.9 \mathrm{Tg}$ during 1984-1988 and 8227.5Tg during 1989-1993, which are $15.50 \%$ and $11.06 \%$ lower than the findings of Fang et al. The findings of $\mathrm{Xu}$ et al are closer to the actual conditions because it considered the influence of forest age on the relationship of biomass and volume of different forest types. More than $80 \%$ of the forest in China is immaturity forest. Most of the original forest has been gradually degraded to secondary forest, even open forest. So the fitted relation between biomass and volume based on trees and ages is a good method to estimate forest biomass.

Zhao et al estimated the carbon stock with hyperbola fitting relationship between biomass and volume.

$B=\frac{\mathrm{v}}{\mathrm{a}+\mathrm{bv}}$

where $\mathrm{a}$ and $\mathrm{b}$ are constant; $\mathrm{B}$ is biomass; $\mathrm{V}$ is volume. The estimation is $7556.2 \mathrm{Tg}$ during 1989-1993, which is $18.31 \%$ lower than the findings of Fang et al. The simple linear relationship between biomass and volume was controversial, and the method of Zhao et al avoids the dispute.

$\mathrm{Li}$ et al estimated the forest biomass in Heilongjiang Province with the method of IPCC.

$B=\mathrm{VD} \cdot B E F_{2} \cdot(1+R)$

where $\mathrm{V}$ is the total volume of a certain forest type; $\mathrm{D}$ is the density of wood of a certain forest type; BEF2 is biomass expansion factor; $\mathrm{R}$ is ratio of root and stem. The forest biomass in Heilongjiang Province is $1625.25 \mathrm{Tg}$ in 2008 , which is only lower $0.35 \%$ than the finding of Guo et al.

\section{The difference of carbon content}

Carbon content is another source that will reduce the difference of forest biomass carbon stock. Researchers at home and abroad often apply 0.45 or 0.5 as carbon content, because it's different to obtain carbon content of all trees. But the carbon content of different types of forest and different organs in a tree may have large difference, which will effects the estimation of forest biomass carbon stock. So is the carbon content of the same type forest of different growth stage and the tree of different origin. Huang et al assayed carbon contents of different forest stands. The findings show that carbon contents were range from $46.75 \%$ to $54.89 \%$, with the average of carbon content is 0.51 . If we change the carbon content with 0.45 , the forest biomass carbon stock will be $349.83 \mathrm{Tg}$, which is lower $12.59 \%$ than the actual finding. If we change the carbon content with 0.5 , the forest biomass carbon stock will be $388.70 \mathrm{Tg}$, which is lower $2.88 \%$ than the actual finding. $\mathrm{Li}$ et al assayed carbon contents of different organs of trees, and then calculated the carbon stocks of trees above ground biomass, which was $747.08 \mathrm{Tg}$. If we change the carbon content with 0.45 , the forest biomass carbon stock will be $688.04 \mathrm{Tg}$, which is lower $7.90 \%$ than the actual finding. If we change the carbon content with 0.5 , the forest biomass carbon stock will be $768.86 \mathrm{Tg}$, which is higher $2.92 \%$ than the actual finding. The study results suggest that taking 0.5 as carbon content is closer to the real value.

\section{The inter-annual of forest biomass carbon pool}

The forest carbon stock dropped continuously during 1949-1959, and forest is carbon source. According to the research of Fang et al, the forest carbon stock decreased 680Tg during the 33 years. In other words, the forest carbon stock decreased $20.67 \mathrm{Tg}$ every year during the 33 years. Forest deforestation is the main reason. Since 1984, the forest carbon stock increased continuously. According to the research of Guo et al, the forest carbon stock dropped during 1994-1998, the finding is mainly come from the statistical error of forest area. The increase of forest area and the growth of forest are contributed to the increase of forest carbon stock. Since the 1970s, the forest plantation and protection were large-scale carried out in China, such as Three-north Forest Protection Project, Yangzi River Protection Forests, Green for Grain Project and so on. These projects increased the area of forest. The adding carbon sink is different in different periods. The minimum adding carbon sink appeared during 1982-1988, which is 9Tg every year. The maximum 
adding carbon sink appeared during 1999-2003, which is 170Tg every year. The increasing of the annual average growth indicated that the carbon sink function of forest is enhanced continuously. The findings of different research about forest carbon sink in China is close, while the findings about adding carbon sink of terrestrial ecosystem carbon pool in North America is much different, and the highest one is about 34 times higher than that of the lowest.

The forest carbon density dropped continuously during 1949-1976. It is mainly caused by the large-scale deforestation of natural forest and mature forest. The forest carbon density fluctuated during 1977-1998, which is mainly because the large plantation of artificial forest and the gradually mature of young forest. The change trends of different studies were basically identical. Xu et al suggested that the forest carbon density reduced during 1994-1998, which is different with other studies. The difference mainly comes from the area of forest. In the study of $\mathrm{Xu}$ et al, there was significant increase in the forest area. While in the study of Fang et al and Guo et al, the forest area was decreased by $281 \times 104$ ha and $730 \times 104$ ha. The difference in forest area is the main source of the difference in the results.

The variation of forest biomass carbon density is determined by the variation of forest types and forest age groups. Forest types include artificial forest and natural forest, and forest age groups include young forest, mid-mature forest and mature forest. Studies have shown that the forest biomass carbon density of artificial forest equivalent of $37.7 \%$ to $57.5 \%$ of the carbon density of natural forest. The forest biomass carbon density of mature forest is about 1.9 times the magnitude of the mid-mature forest, and the forest biomass carbon density of mature forest is about 3.7 times the magnitude of the young forest. As a result, when the proportion of increased area of artificial forest and young forest in the increased area of all forest is relatively big, the forest biomass carbon density will decrease. If the proportion of decreased area of artificial forest and young forest in the decreased area of all forest is relatively big, then the average of carbon density will decrease. When the proportion of increased area of natural forest and mature forest in the increased area of all forest is relatively big, the forest biomass carbon density will increase. If the proportion of decreased area of natural forest and mature forest in the decreased area of all forest is relatively big, then the average of carbon density will decrease. We will take the variation of carbon density since 1977 to 1981 as an example. The carbon stock decreased while the carbon density increased during 1977-1981. The large decreased area of young forest and artificial forest is the main reason. According to Fang' study, the area of artificial forest decreased by $465 \times 104$ ha, which accounts for $82.45 \%$ of the decreased area of all forest. And the carbon density of artificial forest is equivalent of $40.84 \%$ of the average carbon density. In a word, the large decreased area of artificial forest made the increased carbon density. According to $\mathrm{Xu}$ ' study, the area of young forest decreased by $871.96 \times 104 \mathrm{ha}$, which accounts for $83.86 \%$ of the decreased area of all forest. And the carbon density of young forest is equivalent of $42.85 \%$ of the average carbon density. In a word, the large decreased area of young forest made the increased carbon density.

\section{Discussion and prospects}

\section{Improve estimating method of biomass}

There are many methods to estimate forest biomass, including biomass expansion factor function, the model between biomass and volume based on age, hyperbola fitting relationship between biomass and volume, IPCC and regression patterning. The key is to establish regression patterning between biomass and volume which obtained by plot investigation, and then estimate forest biomass based on forest inventory data. But forest inventory data is limited, which can't cover all the forest conditions. It will affect the accuracy of the regression model. Besides, some estimating methods including IPCC exclude the trees whose diameter at breast height is less than $5 \mathrm{~cm}$, which will lead to a lower result. The contribution of trees with small diameter at breast height for forest biomass depends on the stage of succession. Studies have shown that the biomass of trees whose diameter at breast height is less than $10 \mathrm{~cm}$ accounts for $70 \%$ of forest biomass in young broad-leaved forest. So we should improve estimating method of biomass and attach great importance to the representation of the field measured data. How to estimate the biomass of trees whose diameter at breast height is small is a question, we need do more researches. 


\section{Study on other forest carbon stocks}

Estimating forest biomass mainly depends on the data of national forestry inventory no matter in the whole country or yardstick of area. The forest inventory data has many advantages, such as wide distribution and easy accessibility. In addition, the forest inventory data contains almost all the forest types. We have conduct 8 national forestry inventory since the founding of all country. But there are disadvantages to estimate forest biomass based on the national forest inventory data. The national forest inventory only contains the forest whose canopy density is more than 20\%, excluding the forest whose canopy density is less than $20 \%$. According to $\mathrm{Li}$ et al, the carbon stock of the trees including trees in sparse forest, scattered trees and trees planted by the side of farm house and the roads, rivers and fields account for $8.9 \%$ of the carbon stock of high forest in China. The forest carbon stock will be undervalued if only based on the forest inventory data when we estimate the forest carbon stock. Besides standing crop carbon stock, forest biomass carbon stock also include underwood carbon stock, litter carbon stock and coarse woody debris carbon stock. Studies have shown that the biomass of litter accounts for $2 \%-7 \%$ of forest biomass, and the biomass of coarse woody debris accounts for $10 \%-20 \%$ of the above-ground biomass. The fixed carbon content of understory plant accounts for $19.5 \%$ of the forest carbon stock. So we should do more research on the carbon stock of herbs or lianas growing under the canopies, litter and coarse woody debris in order to make a more accurate estimation.

\section{Acknowledgements}

This study is supported by the National Natural Science Foundation of China (Grant No.31370700).

\section{References}

[1] Bonan G.B. 2008. Forests and climate change: forcings, feedbacks, and the climate benefits of forests. Science, 320: 1444-1449.

[2] Dixon R.K. et al. 1994. Carbon pools and flux of global forest ecosystems. Science, 263(5144): 185-190.

[3] Fang J.Y. \& Chen A.P. 2001. Dynamic forest biomass carbon pools in China and their significance. Acta Botanica Sinica, 43: 967-973.

[4] Fang J.Y. et al. 2006. Overestimated biomass carbon pools of the northern mid-and high latitude forests. Climatic Change, 74: 355-368.

[5] Fang J.Y. et al. 2010. Why are East Asian ecosystems important for carbon cycle research. Sci China Life Sci, 40: 561-565..

[6] Goodale C.L. et al. 2002. Forest carbon sinks in the northern Hemisphere. Ecol Appl, 12: 891-899.

[7] Guo Z.D. et al. 2013. Spatio-temporal changes in biomass carbon sinks in China's forests during 1977-2008. Sci China Life Sci, 43(5): 421-431.

[8] Liu G.H. et al. 2000. Carbon dynamics of Chinese forests and its contribution to global carbon balance. Acta ecologica sinica, 20: 733-740.

[9] Liu S.N. et al. 2012. The spatial distribution of forest carbon sinks and sources in China. China Sci Bull, 57: 943-950.

[10]Pacala S.W. et al. 2001Consistent land- and atmosphere-based US carbon sink estimates. Science, 292: 2316-2320.

[11]Pan Y, et al. 2011. A large and persistent carbon sink in the world's forests. Science, 333: 988-993.

[12]Piao S.L. et al. 2012. The carbon balance of terrestrial ecosystems in East Asia over the last two decades. Biogeoscience, 9: 3571-3586.

[13] Wang X.K. et al. 2001. The impact of human disturbance on vegetative carbon storage in forest ecosystems in China. Forest Ecol Manage, 148: 117-123.

[14]Wang X.K. et al. 2001. Vegetation carbon storage and density of forest ecosystems in China. Chinese journal of applied ecology, 12(1): 13-16.

[15] Wu Q.B. et al. 2008. Carbon sequestration and its potential by forest ecosystems in China. Acta Ecologica Sinica, 28(2): 517-524.

[16] Xu X.L. et al. 2007. Temporal-spatial dynamics of carbon storage of forest vegetation in China. Progress in geography, 26: 1-10.

[17] Yang T.H. et al. 2010. The biomass and aboveground net primary productivity of Schima a superba-Castanopsis carlesii forests in east China. Sci China Life Sci, 40: 610-619.

[18]Zhao M \& Zhou G.S. 2004. Carbon storage of forest vegetation and its relationship with climatic factors. Scientia geographica sinica, 24(1): 50-54. 
[19]Zhao M.W. et al. 2013. Spatial distribution of forest vegetation carbon stock in China based on HASM. Acta Geographica Sinica, 68(9): 1212-1224.

[20]Zhou Y.R. et al. 2000. Carbon storage and budget of major Chinese forest types. Acta Phytoecologica Sinica, 24(5): 518-522.

[21]Zhang Q.Z. \& Wang C.K. 2010. Carbon density and distribution of six Chinese temperate forests. Sci China Life Sci, 40: 621-631. 